\title{
Ocular cystinosis
}

INSERM

\section{Source}

INSERM. (1999). Orphanet: an online rare disease and orphan drug data base. Ocular cystinosis. ORPHA:411641

Ocular cystinosis is the benign, adult form of cystinosis (see this term), a metabolic disease characterized by an accumulation of cystine crystals in the cornea and conjunctiva responsible for tearing and photophobia and associated with no other additional manifestations. 